\title{
What is a 'significant portion' of a range? Reply to Nelson et al. (2016)
}

\author{
Robin S. Waples ${ }^{1, *}$, Peter B. Adams ${ }^{2}$, James A. Bohnsack ${ }^{3}$, Barbara L. Taylor ${ }^{4}$ \\ ${ }^{1}$ Northwest Fisheries Science Center, 2725 Montlake Blvd. East, Seattle, WA 98112, USA \\ ${ }^{2}$ Southwest Fisheries Science Center, 110 Shaffer Road, Santa Cruz, CA 95060, USA \\ ${ }^{3}$ Southeast Fisheries Science Center, 75 Virginia Beach Drive, Miami, FL 33149, USA \\ ${ }^{4}$ Southwest Fisheries Science Center, 8604 La Jolla Shores Drive, La Jolla, CA 92037, USA
}

\begin{abstract}
Contrary to the claim by Nelson et al. (2016; Endang Species Res 30:187-190), no court has rejected the biological framework we proposed for interpreting the 'significant portion of its range' (SPOIR) language in the US Endangered Species Act. The relative importance placed on current vs. historical range during implementation will be important in determining the success of the new ESA SPOIR policy.
\end{abstract}

KEY WORDS: Endangered species $\cdot$ Risk analysis $\cdot$ Policy $\cdot$ Anthropocentric

We welcome the opportunity to respond to the comment by Nelson et al. (2016) and to clarify our views on the 'significant portion of its range' (SPOIR) language in the US Endangered Species Act (ESA). To facilitate discussion, we briefly summarize the SPOIR framework we proposed some time ago (Waples et al. 2007). In the scenario under consideration, a species is currently at a level of risk equivalent to threatened or endangered status in part but not all of its range. Let $\mathrm{A}=$ total range and let $\mathrm{B}=$ the range within which the species is currently at risk. The question at hand is how one determines whether B is a 'significant portion' of A. We proposed the following simple test: Assume that at some point in the future, the species has become extirpated from all of area $B$, where it is currently at risk. At that point, would the entire species be threatened or endangered? If so, B is a significant portion of A.

The claims by Nelson et al. (2016) that the SPOIR framework we developed has been rejected by the courts do not hold up to scrutiny. The 2009 Enzler \& Bruskotter article that Nelson et al. (2016) cite as evidence simply repeats the claim made by D'Elia et al. (2008) - that our framework suffers the same prob-

${ }^{*}$ Corresponding author: robin.waples@noaa.gov lem identified by the Ninth Circuit Court of Appeals in its decision in Defenders of Wildlife vs. Norton (2001, 258 F.3d 1136, 1141; 9th Cir.). That Court concluded that the arguments of the US Fish and Wildlife Service (FWS) in that case amounted to claiming that a species is currently threatened or endangered in all or a significant portion of its range only if it is currently threatened or endangered throughout its entire range. As pointed out by Waples et al. (2008), our SPOIR framework does not suffer from that fallacy because it only applies to situations in which the species is not currently threatened or endangered throughout its range. Contrary to the statement by Nelson et al. (2016), the SPOIR framework we developed does not formalize SPOIR interpretations that were rejected by the courts. Neither of the court cases cited in Nelson et al. (2016) have dealt with the SPOIR interpretations that are incorporated into the policy; these cases dealt with previous approaches to SPOIR used by FWS

Nelson et al. (2016) suggest that we overstated their view of how much habitat must be restored before a species is no longer threatened or endangered 'in all or a significant portion of its range.' In Waples et al.

Outside the USA () The Government of the United States 2016. Open Access under Creative Commons by Attribution Licence. Use, distribution and reproduction are unrestricted. Authors and original publication must be credited.

Publisher: Inter-Research · www.int-res.com 
(2015), we focused on 2 opinion-editorial pieces (Vucetich \& Nelson 2014 and Nelson \& Vucetich 2014) that criticized the new SPOIR policy (FWS \& NMFS 2014). The relevant quote from Vucetich \& Nelson (2014) is: 'A more appropriate interpretation of range would be those portions of a species' historical distribution that are suitable, or that can feasibly be made suitable, by mitigating or removing the threats that had caused the species' decline.' Although this passage does not use the word 'all,' neither does it provide any indication that the authors are referring to anything less than all habitat that could be made suitable. If this quote does not actually represent the views of Nelson et al. (2016) on this issue, we apologize. However, after reading Nelson et al.'s Comment, including Appendix 1, we remain puzzled as to how they propose to determine exactly how much less than all of a species' historical distribution must be restored before it no longer can be considered to be threatened or endangered.

We continue to believe that important differences separate our approach from that of Vucetich, Nelson, and colleagues with regard to normative considerations. Certainly we recognize that making listing determinations under the ESA involves both scientific evaluations (quantifying the level of risk) and societal values (deciding how much risk is acceptable) (see e.g. DeMaster et al. 2004, Waples et al. 2013). These issues apply to all listing determinations, whether SPOIR issues are involved or not. The key difference is that our approach avoids, as much as possible, injecting any additional normative considerations into SPOIR evaluations, while the approach suggested by Vucetich et al. (2006) specifically advocates doing just that. A natural consequence of explicitly adding human values to consideration of SPOIR would be confusion, lack of consistency, and inability to predict the outcome of the next SPOIR determination - all limitations that potentially can be reduced by an effective policy.

Nelson et al. (2016) state that our SPOIR approach focuses on current rather than historic range. However, in our original SPOIR paper (Waples et al. 2007), we took pains to emphasize the importance of considering the historical template, which describes the ecological characteristics (abundance, geographic distribution, habitat use, biotic interactions, etc.) that allowed the species to be viable in the past. Subsequently, we published an example (Fig. 1 in Waples et al. 2008) illustrating the dangers of only considering current habitat in SPOIR evaluations. It is true that the 2014 SPOIR policy is ambiguous on this subject, and that is why we noted in Waples et al.
(2015) that how the agencies resolve this issue of current versus historical range in implementing the new policy will be important in determining how successful the policy is.

Contrary to another statement by Nelson et al. (2016), we were not 'architects' of the 2014 SPOIR policy. That policy was developed within the FWS, in consultation with the National Marine Fisheries Service. Our primary contribution was the framework (summarized above) that we developed in 2007; that effort came in response to a request from within our agency for a biologically based approach to address the complexities raised by the SPOIR language in the ESA. Eventually, that framework was incorporated, with some modifications, into the joint interagency policy.

\section{LITERATURE CITED}

D'Elia J, Zwartjes M, McCarthy S (2008) Considering legal viability and societal values when deciding what to conserve under the U.S. Endangered Species Act. Conserv Biol 22:1072-1074

DeMaster D, Angliss R, Cochrane J, Mace P and others (2004) Recommendations to NOAA Fisheries: ESA Listing Criteria by the Quantitative Working Group, 10 June 2004. US Dept. of Commerce, NOAA Tech Memo NMFS-F/SPO-67

FWS \& NMFS (Fish and Wildlife Service and National Marine Fisheries Service) (2014) Final policy on interpretation of the phrase 'significant portion of its range' in the Endangered Species Act's definitions of 'endangered species' and 'threatened species'. Fed Regist 79: 37578-37612

Nelson MP, Vucetich JA (2014) The future of conservation and the tragedy of triage. The Huffington Post, 23 September 2014 (www.huffingtonpost.com/michael-p-nelson/ the-future-of-conservatio_b_5870568.html).

Nelson MP, Vucetich JA, Bruskotter JP (2016) Ecological value and the US Endangered Species Act: Comment on Waples et al. (2015). Endang Species Res 30:187-190

Vucetich JA, Nelson MP (2014) Conservation, or curation? The New York Times, 21 August 2014 (www.nytimes. com/2014/08/21/opinion/conservation-or-curation.html? r $=0$ )

Vucetich JA, Nelson MP, Phillips MK (2006) The normative dimension and legal meaning of endangered and recovery in the U.S. Endangered Species Act. Conserv Biol 20: 1383-1390

Waples RS, Adams PB, Bohnsack J, Taylor BL (2007) A biological framework for evaluating whether an ESA species is threatened or endangered in a significant portion of its range. Conserv Biol 21:964-974

Waples RS, Adams PB, Bohnsack J, Taylor BL (2008) Legal viability, societal values, and SPOIR: response to D'Elia et al. Conserv Biol 22:1075-1077

Waples RS, Nammack M, Cochrane JF, Hutchings JA (2013) A tale of two Acts: endangered species listing practices in Canada and the United States. Bioscience 63:723-734

- Waples RS, Adams PB, Bohnsack JA, Taylor BL (2015) When is a species at risk in 'all or a significant portion of its range'? Endang Species Res 27:189-192 